Gut, 1980, 21, 52-56

\title{
Impaired conversion of prednisone to prednisolone in patients with liver cirrhosis
}

\author{
S MADSBAD, B BJERREGAARD, J H HENRIKSEN, E JUHL, AND \\ H KEHLET
}

From the Second Department of Medicine, Kommunehospitalet, Copenhagen, Division of Hepatology, Department of Medicine, Hvidovre Hospital, Department of Clinical Physiology, Hvidovre Hospital, Copenhagen, and Surgical Department C, Rigshospitalet, Copenhagen

SUMMARY Fourteen patients with liver cirrhosis received oral prednisone or prednisolone $(0 \cdot 3 \mathrm{mg}$ per $\mathrm{kg}$ ) randomised on two consecutive days. Serum prednisone and prednisolone were measured over the following four hours. Mean serum prednisolone concentration after oral prednisone decreased with impaired liver function estimated by galactose elimination capacity $(r=0 \cdot 64$, $\mathbf{P}<0.03)$. Mean serum prednisolone concentration after oral prednisone in the seven patients with severely impaired liver function was only $53 \%(\mathrm{P}<0.05)$ of that observed in the seven patients with slightly impaired liver function. Conversely, mean serum prednisone concentration after oral prednisone in the patients with severely impaired liver function was $74 \%$ higher $(\mathrm{P}=0.05)$ than in patients with slightly impaired liver function. Mean serum prednisolone after oral prednisolone was independent of liver function. As only prednisolone exerts glucocorticoid activity, our results indicate that prednisolone should be preferred to prednisone in the treatment of patients with impaired liver function.

Controlled investigations of the effect of prednisone treatment in chronic liver disease have demonstrated a favourable effect in the majority of patients with non-alcoholic cirrhosis and patients with chronic active hepatitis (Murray-Lyon et al., 1973; Copenhagen Study Group for Liver Diseases, 1974; Summerskill et al., 1975). It is not clear why some patients with these liver disorders do not respond to prednisone treatment. In itself, prednisone has no glucocorticoid effect (Sarett and Patchett, 1963) but must first be converted into prednisolone by 11-hydroxylation, chiefly performed in the liver. A possible explanation of the failure of prednisone treatment, therefore, could be the inability of patients with impaired liver function to carry out the conversion of prednisone to prednisolone. Previous studies on the conversion of prednisone to prednisolone in patients with liver disease are contradictory (Jenkins and Sampson, 1967; Powell and Axelsen, 1972; Uribe et al., 1976; Davis et al., 1978), but in none of these studies was the liver function eval-

Address for reprint requests: S. Madsbad, Hvidøre Hospital, Emiliekildevej 1, DK-2930 Copenhagen, Denmark.

Received for publication 8 August 1979 uated by a quantitative test. The purpose of our study therefore has been to examine the conversion of prednisone to prednisolone with regard to liver function in patients with cirrhosis.

\section{Methods}

PATIENTS

Thirteen men and one woman with liver cirrhosis, verified by biopsy within the past six months, were examined. None of the patients had previously been treated with glucocorticoids. No medications other than diuretics and possibly lactulose, magnesium sulphate, and neomycin were given for three weeks before the start of the investigation. None of the patients had any serious illness but cirrhosis of the liver. Informed consent to taking part was obtained in all instances in accordance with the Helsinki declaration. On two consecutive days at $\mathbf{0 7 3 0}$ hours, after fasting overnight, an indwelling plastic cannula was inserted into a cubital vein. In random order the patients were given orally either $0.30 \mathrm{mg}$ prednisone (Deltasone) or prednisolone (Delta-cortef) per $\mathrm{kg}$ body weight at $\mathbf{0 8 0 0}$ hours, together with $125 \mathrm{ml}$ of water. The exact amount of steroid administered was calculated by dividing and weighing the tablets. Blood samples were drawn 
Table Clinical data in patients with slightly impaired liver function and patients with severely impaired liver function

\begin{tabular}{|c|c|c|c|c|c|}
\hline & \multicolumn{2}{|c|}{$\begin{array}{l}\text { Slightly impaired liver function } \\
n=7\end{array}$} & \multicolumn{2}{|c|}{$\begin{array}{l}\text { Slightly impaired liver function } \\
n=7\end{array}$} & \multirow[t]{2}{*}{ Difference } \\
\hline & Mean & Range & Mean & Range & \\
\hline Age (yr) & $51 \cdot 3$ & $36-57$ & $49 \cdot 6$ & $40-55$ & NS \\
\hline $\begin{array}{l}\text { Weight (kg) } \\
\text { Aspartate aminotransferase }\end{array}$ & $76 \cdot 5$ & $70 \cdot 0-81 \cdot 8$ & $78 \cdot 2$ & $65-91 \cdot 2$ & NS \\
\hline$(10-25 \mathrm{u} / \mathrm{l})$ & $37 \cdot 0$ & $22-63$ & $57 \cdot 4$ & 28-104 & NS \\
\hline Alkaline phosphatase & $87 \cdot 1$ & $58-142$ & $113 \cdot 6$ & $82-130$ & NS \\
\hline S-prothrombin $(60-130 \%)$ & $77 \cdot 5$ & $46-105$ & $42 \cdot 6$ & $30-66$ & $P<0.05$ \\
\hline $\begin{array}{l}\text { S-total bilirubin } \\
(7-14 \cdot 1 \mu \mathrm{mol} / \mathrm{l}) \\
\text { S-albumin }\end{array}$ & $17 \cdot 3$ & $6 \cdot 8-35 \cdot 9$ & $62 \cdot 3$ & $17 \cdot 1-126 \cdot 5$ & $\mathbf{P}=0.05$ \\
\hline $\begin{array}{l}(510-740 \mu \mathrm{mol} / \mathrm{l}) \\
\text { Protein }(\mathrm{g} / \mathrm{l})\end{array}$ & $434 \cdot 7$ & $303 \cdot 9-578 \cdot 8$ & $386 \cdot 4$ & $247 \cdot 8-549 \cdot 9$ & NS \\
\hline $\begin{array}{l}(60-80 \mathrm{~g} / \mathrm{l}) \\
\text { Creatinine }\end{array}$ & $72 \cdot 1$ & $61-82$ & $69 \cdot 0$ & $59-85$ & NS \\
\hline$(50-120 \mu \mathrm{mol} / \mathrm{l})$ & $102 \cdot 5$ & $88 \cdot 4-114 \cdot 9$ & $108 \cdot 7$ & $88 \cdot 4-123 \cdot 8$ & NS \\
\hline
\end{tabular}

after $0,30,60,90,120,150,180,210$, and 240 minutes, during which time the patients remained fasting. The sera were cooled to $-28^{\circ} \mathrm{C}$ until analysis. Prednisone and prednisolone were determined by radioimmunoassay (Colburn and Buller, 1973; Colburn, 1974) on coded samples. On the first day of investigation additional analyses were made of serum aspartate aminotransferase, alkaline phosphatase, prothrombin, albumin, and creatinine. On the third day of investigation, galactose elimination capacity (GEC) was measured after intravenous injection of $0.5 \mathrm{~g}$ galactose per $\mathrm{kg}$ body weight as described by Tygstrup (1963). According to the results of the GEC the 14 patients were arbitrarily divided into two groups. One group with slightly impaired liver function, mean GEC $2 \cdot 14 \mathrm{mmol} / \mathrm{min}$, range $1 \cdot 80-2 \cdot 54 \mathrm{mmol} / \mathrm{min}$ (no. $=7$ ). The second group with severely impaired liver function, mean GEC $1.35 \mathrm{mmol} / \mathrm{min}$, range $1.05-1.58 \mathrm{mmol} / \mathrm{min}$ $($ no. $=7)$. The remaining laboratory values of the two groups are shown in the Table.

As the time course of serum concentrations of prednisone and prednisolone was followed for only four hours, half-life values were not calculated. As an expression of the mean concentration of the two compounds during the four-hour period, the area under the respective curves was used.

For statistical estimations the Mann-Whitney rank sum test or Wilcoxon's test was used to compare mean concentrations of prednisone and prednisolone. Spearman's test was used to compare GEC and mean plasma prednisolone concentration

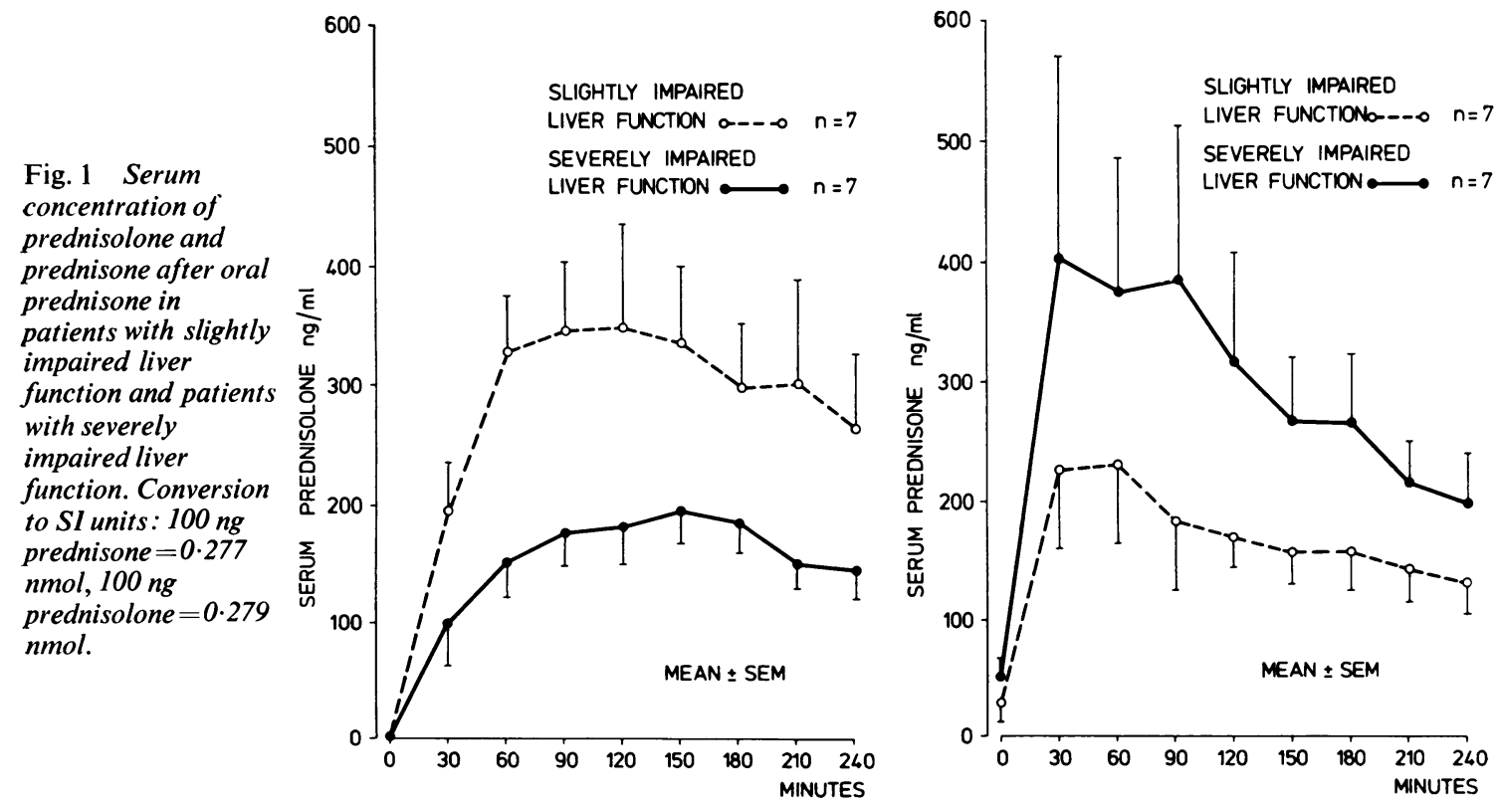



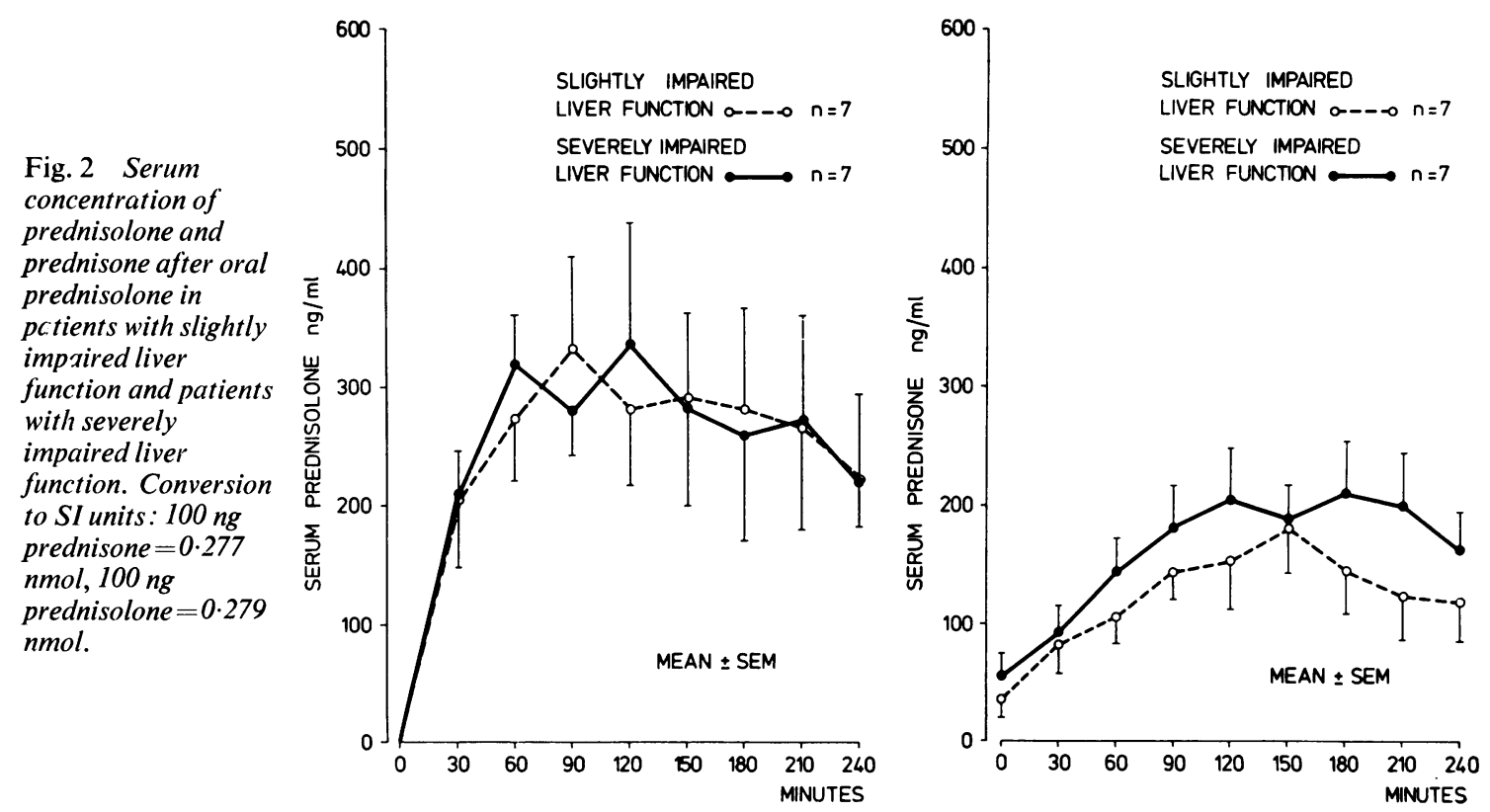

after prednisone. The level of statistical significance was $2 \alpha=0.05$.

\section{Results}

The serum concentrations of prednisone and prednisolone after oral administration of prednisone are shown in Fig. 1. The area under the prednisolone curve of the group with severely impaired liver function constituted only $53 \%$ of the area under the prednisolone curve of the group with slightly impaired liver function $(\mathrm{P}<0.05)$. The average maximal concentrations of prednisolone after oral prednisone were $348 \mathrm{ng} / \mathrm{ml}$ and $195 \mathrm{ng} / \mathrm{ml}$ in the group with slightly and severely impaired liver function respectively. Conversely, the area under the prednisone curve (Fig. 1) of the group with severely impaired liver function was found to be $74 \%$ higher than the area under the prednisone curve of the group with slightly impaired liver function $(P=0.05)$. The average maximal concentrations of prednisone were $403 \mathrm{ng} / \mathrm{ml}$ and $230 \mathrm{ng} / \mathrm{ml}$ in the group with severe and slight liver function impairment, respectively.

Figure 2 shows the serum concentrations of prednisone and prednisolone after oral administration of prednisolone. There was no significant difference between the two groups with respect to the time course of concentrations or to the maximal concentrations of prednisone and prednisolone.

In the group with slightly impaired liver function there was no significant difference in the area under the serum prednisolone curves after oral prednisone (Fig. 1) or prednisolone (Fig. 2).

In the group with severely impaired liver function the area under the prednisolone curve (Fig. 1) after intake of prednisone constituted $59 \%$ of the area under the prednisolone curve (Fig. 2) after intake of prednisolone $(\mathrm{P}<0.05)$.

After intake of prednisone, the correlation between the mean serum prednisolone concentration and the GEC during the four-hour observation period in individual patients is plotted in Fig. 3. It can be seen that declining liver function was accompanied by lower serum prednisolone values after oral administration of prednisone $(r=0.64, \mathrm{P}<0.03)$.

\section{Discussion}

In 1967 Jenkins and Sampson (1967) reported an almost unchanged conversion of prednisone to prednisolone in two patients with not clearly defined liver function. Powell and Axelsen (1972) studied six patients with acute hepatitis and 16 patients with chronic liver disease of whom nine had 'active' liver disease. In the groups with 'active' liver disease and acute hepatitis peak plasma prednisolone was found to be about $15 \%$ higher after oral prednisolone than after prednisone. On the other hand, there was no difference in the prednisolone concentrations after oral prednisone or prednisolone in the group with chronic inactive liver disease. In two other studies (Uribe et al., 1976; Davis et al., 1978), in which the liver function was not defined, no 


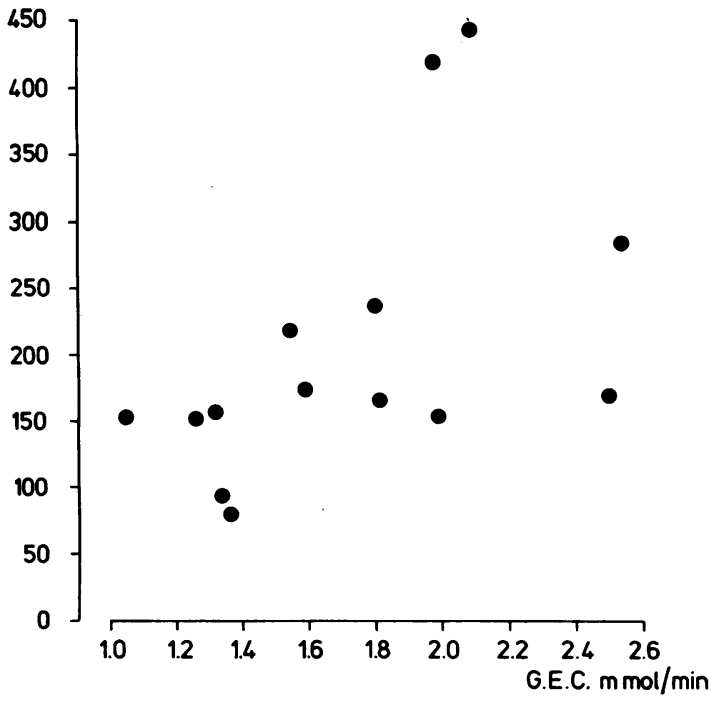

Fig. 3 Correlation between mean serum concentration of prednisolone $(\mathrm{ng} / \mathrm{ml})$ after oral prednisone $(03.0$ $\mathrm{mg} / \mathrm{kg}$ ) and liver function as expressed by galactose elimination capacity $(G E C)(r=0.64, \mathrm{P}<0.03)$. Conversion to SI units: $100 \mathrm{ng}$ prednisone $=0.277 \mathrm{nmol}, 100 \mathrm{ng}$ prednisolone $=0.279 \mathrm{nmol}$.

major difference in plasma prednisolone was found after oral prednisone between patients with chronic active liver disease and normal individuals, although patients with liver disease showed a delayed appearance of plasma prednisolone peak concentration; however, plasma half-life of prednisolone was slightly prolonged making the plasma concentrationtime curve similar to normal subjects (Davis et al., 1978).

Our study differs from the above-mentioned studies in that we have attempted a quantitative estimation of liver function. Among the numerous laboratory analyses (Table) available for evaluation of liver function, the maximal uptake rate of galactose by the liver (GEC) is presumably one of the best methods for evaluation of liver function (functional liver cell mass, Tygstrup, 1973). From a biochemical point of view, GEC measures the maximal rate of phosphorylation, and thus is an indicator of one of the basic liver functions. In rats receiving carbon tetrachloride, GEC was reduced parallel to the damage of the liver (Vilstrup, 1978), and, in the isolated perfused pig liver, GEC and ATP were both reduced parallel to the degree of hypoxia (Rabøl et al., 1974). Furthermore, in man, GEC shows a positive correlation with other hepatic tolerance tests as antipyrin clearance and $\mathrm{Tm}$ of bromsulphalein (Andreasen et al., 1974). In patients with fulminant hepatic failure, GEC is significantly higher in patients who survive compared with those with a fatal outcome (Ranek et al., 1976). In patients with hepatic cirrhosis, GEC shows a good correlation with prognosis (Tygstrup, 1964). A positive correlation was found between the mean prednisolone concentration after oral prednisone and the galactose elimination capacity. After intake of prednisone mean prednisolone concentration in patients with severely impaired liver function was only $53 \%$ of that observed in patients with slightly impaired liver function. Conversely, mean prednisone concentration in patients with severely impaired function was $74 \%$ higher than in patients with slightly impaired liver function. As the total glucocorticoid level (prednisone plus prednisolone) after oral prednisone was similar in patients with severely and slightly impaired liver function the observed differences cannot be explained by differences in absorption between the two patient groups. The differences in prednisolone values after oral prednisone might be expected to be equalised if prednisolone metabolism was deficient in the patients with severely impaired liver function. However, this is unlikely, as plasma prednisolone values were similar in patients with slightly and severely impaired liver function after oral prednisolone (Fig. 2). The low values of prednisone detectable even before steroid administration may be due to cross-reactivity from endogenous cortisone and cortisol (Colburn, 1974).

Our results indicate that the liver function must be considerably impaired before a difference can be detected in the serum prednisolone concentrations after oral administration of prednisone and prednisolone, respectively.

The practical clinical significance of the demonstrated impaired conversion of prednisone to prednisolone is not yet clear. In a recently published study (Schalm et al., 1977), in which patients with chronic active liver disease were divided into one group which responded to prednisone treatment and into another which did not respond, the serum concentrations of prednisolone after intravenous administration of $10 \mathrm{mg}$ prednisone were found to be only $15 \%$ lower in the group which did not respond than in the group which did respond. From these results the authors concluded that the therapeutic ineffectiveness of prednisone must be considered to be caused by factors other than an impaired conversion to prednisolone.

On the basis of our results we conclude that in relation to the amount of prednisone administered the level of serum prednisolone in patients with severely impaired liver function is less than expected. As prednisolone, unlike prednisone, exerts biological glucocorticoid activity without undergoing metabolic 
conversion, prednisolone should be preferred to prednisone in glucocorticoid treatment of patients suffering from liver diseases.

We are grateful to Upjohn Company, Kalamazoo, Michigan, USA for performing the serum analyses of prednisone and prednisolone.

\section{References}

Andreasen, P. B., Ranek, L., Statlana, B. E. and Tygstrup, N. (1974). Clearance of antipyrine-dependence of quantitative liver function. European Journal of Clinical Investigation, 4, 129-134.

Colburn, W. A. (1974). Radioimmunoassay for prednisone. Steroids, 24, 95-106.

Colburn, W. A., and Buller, R. H. (1973). Radioimmunoassay for prednisolone. Steroids, 21, 833-846.

Copenhagen Study Group for Liver Diseases (1974). Sex, ascites and alcoholism in survival of patients with cirrhosis. New England Journal of Medicine, 291, 271-273.

Davis, M., Williams, R., Chakraborty, J., English, J., Marks, V., Ideo, G., and Tempini, S. (1978). Prednisone or prednisolone for the treatment of chronic active hepatitis? A comparison of plasma availability. British Journal of Clinical Pharmacology, 5, 501-505.

Jenkins, J. S., and Sampson, P. A. (1967). Conversion of cortisone to cortisol and prednisone to prednisolone. British Medical Journal, 2, 205-207.

Murray-Lyon, I. M., Stern, R. B., and Williams, R. (1973). Controlled trial of prednisone and azathioprine in active chronic hepatitis. Lancet, 1, 735-737.

Powell, L. W., and Axelsen, E. (1972). Corticosteroids in liver disease: studies on the biological conversion of prednisone to prednisolone and plasma protein binding. Gut, 13, 690-696.

Rabøl, A., Hansen, F. V., Keiding, S., Tygstrup, N., Tønnesen, K., and Winkler, K. (1974). The effect of hypoxia on the function of the isolated perfused pig liver (Abstract). Digestion, 10, 375.
Ranek, L., Andreasen, P. B., and Tygstrup, N. (1976). Galactose elimination capacity as a prognostic index in patients with fulminant liver failure. Gut, 17, 959964.

Sarett, L. H., Patchett, A. A., and Steelman, S. L. (1963). The effects of structural alteration on the anti-inflammatory properties of hydrocortisone. Fortschritte der Arzneimittelforschung. Progress in Drug Research. 5, 11-153.

Schalm, S. W., Summerskill, W. H. J., and Go, V. L. W. (1977). Prednisone for chronic active liver disease: Pharmacokinetics, including conversion to prednisolone. Gastroenterology, 72, 910-913.

Summerskill, W. H. J., Korman, M. G., Ammon, H. V., and Baggenstoss, A. H. (1975). Prednisone for chronic active liver disease: dose titration, standard dose, and combination with azathioprine compared. Gut, 16, 876-883.

Tygstrup, N. (1963). Determination of the hepatic galactose elimination capacity after a single intravenous injection in man, the reproducibility and the influence of uneven distribution. Acta Physiologica Scandinavica, 58, 162-172.

Tygstrup, N. (1964). The galactose elimination capacity in relation to clinical and laboratory findings in patients with cirrhosis. Acta Medica Scandinavica, 175, 291-300.

Tygstrup, N. (1973). The concept of the functional liver mass in the assessment of liver function. In Liver: Proceedings of an International Liver Conference, pp. 392-401. Edited by J. S. Saunders and J. Terblanche. Pitman Medical: London.

Uribe, M., Go, V. L. W., and Summerskill, W. H. J. (1976). Kinetics and interconversion of prednisone and prednisolone in chronic active liver disease (CALD) after oral doses (Abstract). Gastroenterology, 71, A39-932.

Vilstrup, H. (1978). The galactose elimination capacity as a quantitative measure of liver function in acute carbon tetrachloride intoxication of rats. European Journal of Clinical Investigation, 8, 317-319. 